\title{
RELAÇÃO ENTRE A RADIAÇÃO DE ONDA LONGA, PRECIPITAÇÃO E TEMPERATURA DA SUPERFÍCIE DO MAR NO OCEANO ATLÂNTICO TROPICAL
}

\author{
Tiago Nicolosi Bomventi ${ }^{1}$, Ilana Elazari Klein Coaracy Wainer ${ }^{2}$ e Andrea Sardinha Taschetto ${ }^{3}$ \\ Recebido em 5 junho, 2006 / Aceito em 28 dezembro, 2006 \\ Received on June 5, 2006 / Accepted on December 28, 2006
}

\begin{abstract}
Deep convection processes associated with sea surface temperature (SST) is an important mechanism of thermal control, redistributing the sea surface energy to high levels of atmosphere. Tropical areas of warmer SST are usually associated with areas of high precipitation. The present work examines the degree of spatial and temporal correlation, existing between outgoing longwave radiation (OLR), precipitation (PPT) and SST in the Tropical Atlantic 0 cean $\left(20^{\circ} \mathrm{N}-20^{\circ} \mathrm{S}\right)$. It was verified that the area of highest spatial correlation among PPT, OLR and SST is located to the north of Equator, following the displacement of the Intertropical Convergence Zone (ITCZ). In the tropics, there are regions where the SST-OLR correlation presents different values, suggesting that would be the action of remote processes affecting differently these variables. The dispersion diagrams of OLR $\times$ SST for significant values of correlation, present a break of the trend when the SST is around 27 to $28^{\circ} \mathrm{C}$, indicating a transition of the state when deep convection occurs. The maximum precipitation occurs for SST near $28^{\circ} \mathrm{C}$.
\end{abstract}

Keywords: ocean-atmosphere interaction, OLR, SST, precipitation.

RESUMO. 0 processo de convecção profunda, associado à Temperatura da Superfície do Mar (TSM) é um importante mecanismo de controle térmico, redistribuindo a energia da superfície do mar para maiores níveis da atmosfera. Áreas tropicais de elevada TSM normalmente estão associadas a áreas com altos índices de precipitação. 0 presente trabalho examina 0 grau de correlação espacial e temporal existente entre a Radiação de Onda Longa (ROL) emitida, a precipitação (PREC) e a TSM no Oceano Atlântico Tropical $\left(20^{\circ} \mathrm{S}-20^{\circ} \mathrm{N}\right)$. Verificou-se que a área de maior correlação espacial entre a PREC, ROL e TSM se situa ao norte do Equador, acompanhando 0 deslocamento da Zona de Convergência Intertropical (ZCIT). Na região tropical, existe locais onde a correlação entre a TSM e a ROL apresenta valores diferentes, uma possível explicação seria a ação de processos remotos afetando de maneira diferente essas variáveis. Os diagramas de dispersão ROL $\times$ TSM para valores significativos de correlação, apresentam uma quebra de tendência nos pontos quando a TSM atinge a faixa de 27 à $28^{\circ} \mathrm{C}$, indicando uma transição do estado em que se inicia a convecção profunda. A máxima precipitação ocorre para TSM próxima de $28^{\circ} \mathrm{C}$.

Palavras-chave: interação oceano-atmosfera, ROL, TSM, precipitação.

\footnotetext{
${ }_{1}^{1}$ Laboratório de Meteorologia Marinha (LABMet), Instituto Oceanográfico, Universidade de São Paulo, Praça do Oceanográfico, 191, 05508-900 São Paulo, SP, Brasil. Tel: (11) 3091-6581; Fax: (11) 3091-6610 - E-mail: tiagonb@gmail.com

${ }^{2}$ Laboratório de Meteorologia Marinha (LABMet), Instituto Oceanográfico, Universidade de São Paulo, Praça do Oceanográfico, 191, 05508-900 São Paulo, SP, Brasil. Tel: (11) 3091-6562; Fax: (11) 3091-6610 - E-mail: wainer@usp.br

${ }^{3}$ Climate \& Environmental Dynamics Laboratory (CEDL), School of Mathematics and Statistics, University of New South Wales, UNSW, Sydney, 2052, Australia. Phone: (+61) 02 9385-4628; Fax: (+61) 02 9385-7123 - E-mail: a.taschetto@unsw.edu.au
} 


\section{INTRODUÇÃ̃o}

Praticamente toda a energia do sistema Terra provém da radiação solar (Radiação de Onda Curta), existindo um balanço quase perfeito entre a radiação solar incidente e a radiação emitida pela Terra para o espaço (Radiação de Onda Longa). Outra parte do balanço de energia ocorre na forma de calor latente, associado à evaporação na superfície, e ao calor sensível (condução de calor).

0 processo de ascensão vertical de uma massa de ar aquecida pela superfície, redistribui a energia de camadas mais baixas para maiores altitudes. A convecção profunda atinge a alta troposfera onde grande parte do vapor de água se condensa. 0 processo convectivo é considerado um importante processo de extração de calor da superfície (Lindzen, 1990). 0 estudo dos mecanismos que atuam no processo de convecção profunda e sua relação com a temperatura da superfície da água são importantes porque junto com as correntes oceânicas regulam 0 clima do planeta.

Para as regiões tropicais, baixos valores de radiação de onda longa (ROL) registrados pelo satélite no topo da atmosfera terrestre são utilizados para caracterizar regiões de convecção profunda, enquanto que em médias latitudes, similares valores de ROL podem representar nuvens do tipo Stratus (Dutton et al., 2000). A convecção tropical, geralmente corresponde a regiões de ROL abaixo de $240 \mathrm{Wm}^{-2}$ (Lau et al., 1997).

Existem controvérsias acerca do papel da ROL em caracterizar a convecção profunda, pois um dos maiores problemas é distinção entre os diferentes tipos de nuvens que não envolvem precipitação bastante comuns na cobertura aérea de larga-escala, pois elas se expandem por quilômetros para além de sua região de formação. Portanto, um baixo valor de ROL é determinado pela quantidade de nuvens altas, principalmente Cirrus, mas não mede diretamente a quantidade de nuvens convectivas profundas. Por outro lado, os Cirrus são produto natural da convecção profunda e não podem se desenvolver e nem se manter sem uma fonte convectiva identificável nos trópicos. Zhang (1993) conclui que a ROL pode não servir para identificar nuvens de convecção profunda, mas pode ser usada de maneira confiável, principalmente em grandes escalas de tempo, para detectar áreas de atividade convectiva que estão associadas com a formação de nuvens de convecção profunda.

Acredita-se que a precipitação esteja diretamente relacionada a ROL, já que para a região tropical, onde a TSM varia modestamente ao longo do ciclo anual, as maiores variações de ROL resultam de mudanças na quantidade e na altura das nuvens. Essa ligação direta com nuvens fez com que a ROL passasse a ser utilizada para estimar quantitativamente a precipitação. Na região tropical a maior parte da precipitação está associada à convecção profunda (Xie \& Arkin, 1998). Regiões de intensa e freqüente convecção e precipitação, associadas às monções e à Zona de Convergência InterTropical (ZCIT) aparecem como regiões de baixa ROL (Chelliah \& Arkin, 1992).

0 estudo da relação ROL-TSM e da precipitação já foi assunto para muitas pesquisas no Oceano Pacífico, devido à presença da piscina de água quente e sua influência em processos climáticos como 0 El-Niño. A região de maior precipitação no Pacífico tropical se encontra exatamente na ZCIT, localizada a $5^{\circ} \mathrm{N}$, apresentando média anual superior a 3000 mm (Tomzcak \& Godfrey, 2003), e variando bastante entre a porção oeste (água quente) com a porção leste (água mais fria).

Lau et al. (1997) em seu estudo analisou a ROL, TSM e divergência dos ventos em 200-mb, tentando olhar de maneira desacoplada a relação entre TSM e convecção profunda e desconsiderando a dinâmica de circulação atmosférica de larga-escala. Os autores concluíram ser impossível isolar com uma visão clara a influência de qualquer uma das duas variáveis quando estas estão desacopladas de uma terceira. Zhang (1993) relacionou as regiões de convecção profunda com áreas de elevada TSM para a região da piscina de água quente do Pacífico, porém a convecção profunda só é intensa para uma certa faixa de $\mathrm{TSM}$, de $26^{\circ} \mathrm{C}$ até $30^{\circ} \mathrm{C}$. Para TSM mais elevadas a atividade convectiva decai.

0 Oceano Índico também já foi bastante estudado por influenciar diretamente o clima da região no sul da Ásia. A principal diferença entre o Índico e os outros oceanos consiste na barreira continental em sua porção subtropical norte, que empilha as massas de água equatoriais, impedindo sua mistura e mantendo a TSM relativamente alta. A precipitação é muito mais intensa na região leste, próximo à Sumatra (3000 mm por ano) do que na região oeste na costa da Arábia (100 mm por ano) (Tomzcak \& Godfrey, 2003). A TSM permanece acima dos $28,5^{\circ} \mathrm{C}$ com exceção da costa da Somália, porção oeste do Índico, onde a TSM decai no período de verão devido a uma ressurgência resultante dos ventos das monções. 0 regime de ventos das monções é importante para a região pois regula diretamente a precipitação. Embora ocorra na África e na Ásia, é na Índia que as monções mais se destacam. Entre junho e setembro, as chuvas trazidas pelas monções de verão acabam por favorecer 0 desenvolvimento das plantações de arroz que sustenta um décimo da população mundial.

0 0ceano Atlântico possui a região de máxima precipitação associada ao posicionamento da ZCIT, que durante a maior parte do ano permanece no hemisfério norte, com uma média superior 
a $2000 \mathrm{~mm}$ por ano. Na faixa do Atlântico tropical predomina a TSM média máxima superior a $27^{\circ} \mathrm{C}$.

0 estudo da relação entre TSM e precipitação no Atlântico Tropical, já foi abordado por diversos autores, Moura \& Shukla (1981) e Servain (1991), e mais recentemente em um estudo de simulação numérica (Pezzi \& Cavalcanti, 2001).

Apesar de existirem estudos sobre o Oceano Atlântico envolvendo a relação TSM-ROL (Graham \& Barnett, 1987), 0 assunto ainda não foi devidamente abordado. Diferentemente do Oceano Pacífico, a relação TSM-ROL no Oceano Atlântico foi bem menos estudada. Mesmo com as pesquisas científicas, muitas dúvidas ainda permanecem, pois a convecção profunda envolve uma série de parâmetros que agem de maneira acoplada.

0 objetivo desse estudo é verificar a estrutura espacial e temporal da correlação entre TSM, ROL e PREC para a região do Oceano Atlântico Tropical.

\section{METODOLOGIA}

Para esse estudo foram utilizadas três variáveis de diferentes fontes: TSM, ROL e PREC.

Os dados de TSM são provenientes de Reynolds et al. (2002). Esse conjunto de dados foi gerado a partir de uma interpolação ótima onde se utiliza uma mistura de dados de navios, bóias e satélites para se determinar os campos de TSM. Os dados são mensais, correspondendo a médias de valores diários registrados durante o mês para o período de 1 de dezembro de 1981 até 30 de fevereiro de 2004. A cobertura espacial é de $1^{\circ} \times 1^{\circ}$, estendendo-se de $0,5^{\circ} \mathrm{W}$ e $89,5^{\circ} \mathrm{S}$ até $0,5^{\circ} \mathrm{E}$ e $89,5^{\circ} \mathrm{N}$.

Os dados de ROL foram obtidos do Centro de Previsão Climática (CPC) da NOAA que fornece as médias mensais globais de radiação de onda longa em $\mathrm{Wm}^{-2}$ (Liebmann \& Smith, 1996). A grade de ROL é igualmente espaçada em $2,5^{\circ}$ de latitude e longitude, cobrindo todo o globo. 0 período dos dados compreende de junho de 1974 a julho de 2004.

Os dados de PREC provêm do "CPC Merged Analysis of Precipitation" (CMAP). 0 arquivo contém os valores das médias mensais da taxa de PREC (mm/dia) (Xie \& Arkin, 1997). Os dados são obtidos de 5 satélites diferentes (GPI, OPI, SSM/I scattering, SSM/I emission e MSU) além de incluir valores da Re-análise do NCEP/NCAR. A resolução espacial dos dados é $2,5^{\circ}$ na latitude e longitude para todo o globo. 0 período dos dados compreende janeiro de 1979 a agosto de 2003.

Com 0 intuito de unificar a cobertura espacial dos diferentes conjuntos de dados, a TSM foi interpolada para uma grade de menor resolução (2,5॰ latitude $\times$ 2,5॰ longitude). Em relação à escala temporal, as séries foram definidas de janeiro de 1982 até dezembro de 2002 para todos os conjuntos de dados.

Para caracterizar o comportamento médio do Atlântico Tropical, calculou-se a climatologia mensal das variáveis de ROL, PREC e TSM, entre as latitudes de $30^{\circ} \mathrm{N}$ a $30^{\circ} \mathrm{S}$ e longitudes de $75^{\circ} \mathrm{W}$ a $30^{\circ} \mathrm{E}$. Além da distribuição espacial no Atlântico Tropical, a variação sazonal da PREC, ROL e TSM com a latitude foi analisada através de um diagrama Latitude vs. Tempo.

Calculou-se os ciclos climatológicos a partir das médias dos meses de cada ano para cada parâmetro e estes foram subtraídos das séries temporais para se obter a anomalia. A partir dos ciclos climatológicos anuais e das séries temporais das anomalias foram calculadas as correlações entre a TSM, ROL e PREC para localizar as regiões de maior acoplamento entre essas variáveis. Dessa maneira também foi possível observar o quanto das correlações encontradas correspondiam a série climatológica. Quatro séries temporais foram selecionadas a partir do mapa de correlação ROL-TSM para uma investigação mais detalhada sobre as diferentes relações entre as variáveis aqui estudadas. Assim, foi possível exibir diagramas de dispersão para cada um dos pontos específicos da área de estudo. Em seguida, esses pontos foram estudados através dos valores de alta correlação TSMPREC ( $\geq 0.6$ ) e TSM-ROL ( $\leq-0.6$ ) na região delimitada entre $15^{\circ} \mathrm{N}-5^{\circ} \mathrm{S}$.

Para localizar a temperatura crítica na qual a convecção profunda começa a agir, diagramas de dispersão foram plotados para os pontos de TSM e PREC para a faixa de ROL de 230-250 $\mathrm{Wm}^{-2}$ e para ROL $<240 \mathrm{Wm}^{-2}$. Segundo Lau et al. (1997), o valor crítico que caracteriza 0 início da atividade convectiva é a ROL inferior a $240 \mathrm{Wm}^{-2}$. Nesse trabalho adotamos esse valor crítico para estimar a probabilidade de ocorrência dessa ROL. Portanto, foi contabilizado o número total de observações para todas as faixas de ROL e para valores inferiores a 240 W. $\mathrm{m}^{-2}$. Assim, pôdese determinar o seguinte índice:

$$
\text { Probabilidade }_{R O L<240}=\frac{X_{R O L<240}}{X_{R O L_{\text {total }}}}
$$

Por fim, foram feitas estimativas da probabilidade de ocorrência de ROL para determinadas faixas de TSM, através da divisão do número de observações de ROL encontrado para cada faixa de TSM $\left(26-27^{\circ} \mathrm{C}, 27-28^{\circ} \mathrm{C}\right.$ e $\left.28-29^{\circ} \mathrm{C}\right)$ pelo valor total de observações de ROL para todo o domínio da TSM, isto é, de 14 a $30^{\circ} \mathrm{C}$

$$
\begin{gathered}
\text { Probabilidade }_{R O L<240 \rightarrow T S M\left(26-26,5^{\circ} \mathrm{C}\right)} \\
=\frac{X_{R O L<240 \rightarrow T S M\left(26-26,5^{\circ} \mathrm{C}\right)}}{X_{R O L_{\text {total }} \rightarrow T S M\left(14-30^{\circ} \mathrm{C}\right)}}
\end{gathered}
$$



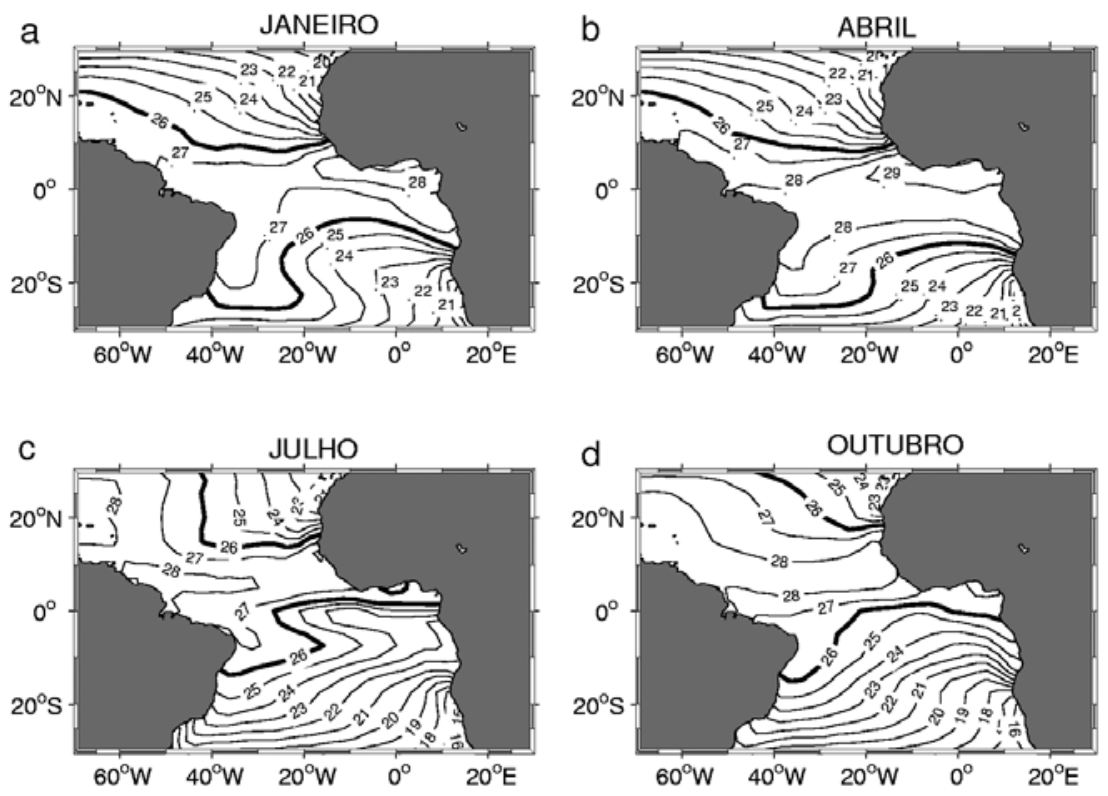

Figura 1 - Temperatura da superfície do mar (TSM) média para os meses de (a) janeiro, (b) abril, (c) julho, (d) outubro, no Atlântico Tropical. Em destaque a região com TSM superior a $26^{\circ} \mathrm{C}$. 0 intervalo das isolinhas é de $1^{\circ} \mathrm{C}$.

\section{RESULTADOS E DISCUSSÕES Climatologia}

As Figuras 1 a 3 apresentam a distribuição espacial da TSM, ROL e PREC para a região do Atlântico Tropical. Foi utilizada a média climatológica dos meses de janeiro, abril, julho e outubro, ao longo de 20 anos, para caracterizar as feições de cada estação do ano.

A distribuição sazonal da TSM no Atlântico Tropical pode ser vista na Figura 1. 0 Atlântico Tropical mostra, como esperado, isotermas com maiores valores ao longo do equador e a diminuição dessas temperaturas com maiores latitudes devido à influência direta da radiação solar incidente sobre a superfície. Essas isotermas não são completamente zonais, delimitando a bacia de água quente no lado oeste do oceano. Contudo, 0 Atlântico apresenta um padrão de distribuição da TSM e de vento, dentro do ciclo anual e da variabilidade interanual, de estrutura norte-sul mais pronunciada do que a estrutura leste-oeste (Nobre, 1996). Na Figura 1 pode-se observar essa variação através da isoterma de $26^{\circ} \mathrm{C}$ que se desloca de sul para norte no decorrer do ano. Em janeiro e abril (Figura 1a e 1b) a faixa de $26^{\circ} \mathrm{C}$ está entre $20^{\circ} \mathrm{N}$ e $25^{\circ} \mathrm{S}$, é a passagem do verão para o outono no hemisfério sul. Em julho e outubro (Figura 1c e 1d) a faixa se desloca bastante para o norte, até aproximadamente $15^{\circ} \mathrm{S}$, quando é a passagem do inverno para a primavera no hemisfério sul.

Esse padrão de deslocamento meridional se repete na distri- buição da ROL (Figura 2) e na distribuição da PREC (Figura 3). Na Figura 2(a-d) está explicitada a linha de $240 \mathrm{Wm}^{-2}$, valor que representa o mínimo de ROL, para se identificar regiões de convecção profunda. Essa faixa de ROL $\left(<240 \mathrm{Wm}^{-2}\right)$ se desloca entre 0 sul e o norte do equador meteorológico $\left(5^{\circ} \mathrm{N}\right)$, nos meses de julho e outubro (Figura 2c e 2d). A faixa $<240 \mathrm{Wm}^{-2}$ está acima dos $5^{\circ} \mathrm{N}$ e nos meses de janeiro e abril (Figura 2a e 2b) se desloca para baixo dos $5^{\circ} \mathrm{N}$.

$\mathrm{Na}$ Figura 2 nota-se menores valores de ROL ao longo do equador, representando o posicionamento da ZCIT e maiores valores nos subtrópicos (faixa de $270 \mathrm{Wm}^{-2}$ no meio do oceano Atlântico) indicando as regiões de subsidência de ar. Devido à ausência de nuvens, mais radiação solar atinge a superfície que, associada ao baixo albedo, é quase integralmente absorvida pelo oceano. Como conseqüência, essas regiões emitem mais ROL para o espaço. 0 padrão da PREC (Figura 3) se assemelha bastante com 0 padrão da ROL, onde 0 máximo de precipitação ocorre dentro da faixa de $240 \mathrm{Wm}^{-2}$, localizado no equador meteorológico, e um mínimo na região de ROL $>260 \mathrm{Wm}^{-2}$, corresponde à região de subsidência de ar.

A Figura 3 mostra a faixa de intensa PREC sobre 0 oceano em torno do equador localizando a ZCIT. Verifica-se que 0 mês de outubro apresenta valores mais intensos de PREC alcançando $12 \mathrm{~mm} \cdot \mathrm{dia}^{-1}$ em $30^{\circ} \mathrm{W} / 7^{\circ} \mathrm{N}$, aproximadamente. Também observa-se grandes áreas de baixa PREC nos 

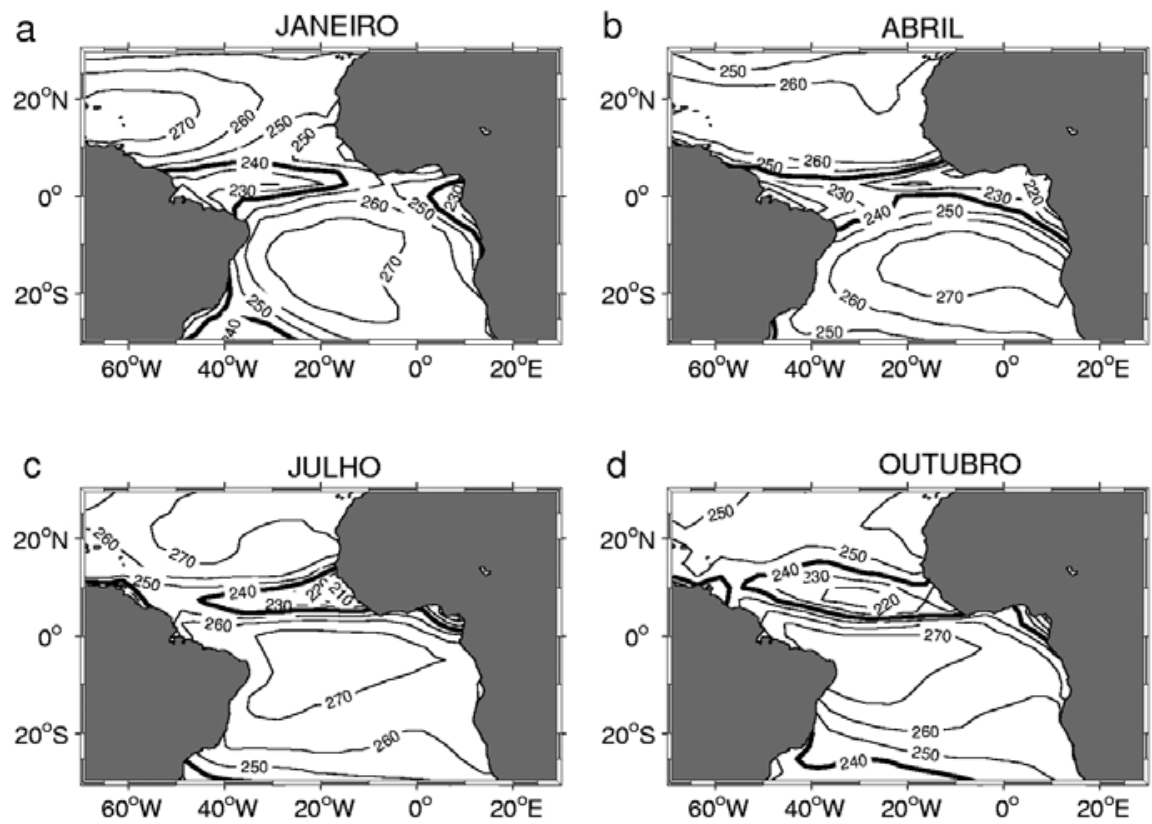

Figura 2 - Radiação de onda longa (ROL) média para os meses de (a) janeiro, (b) abril, (c) julho e (d) outubro, no Atlântico Tropical. Em destaque a região com ROL superior a $240 \mathrm{Wm}^{-2}$. 0 intervalo das isolinhas é de $10 \mathrm{Wm}^{-2}$.
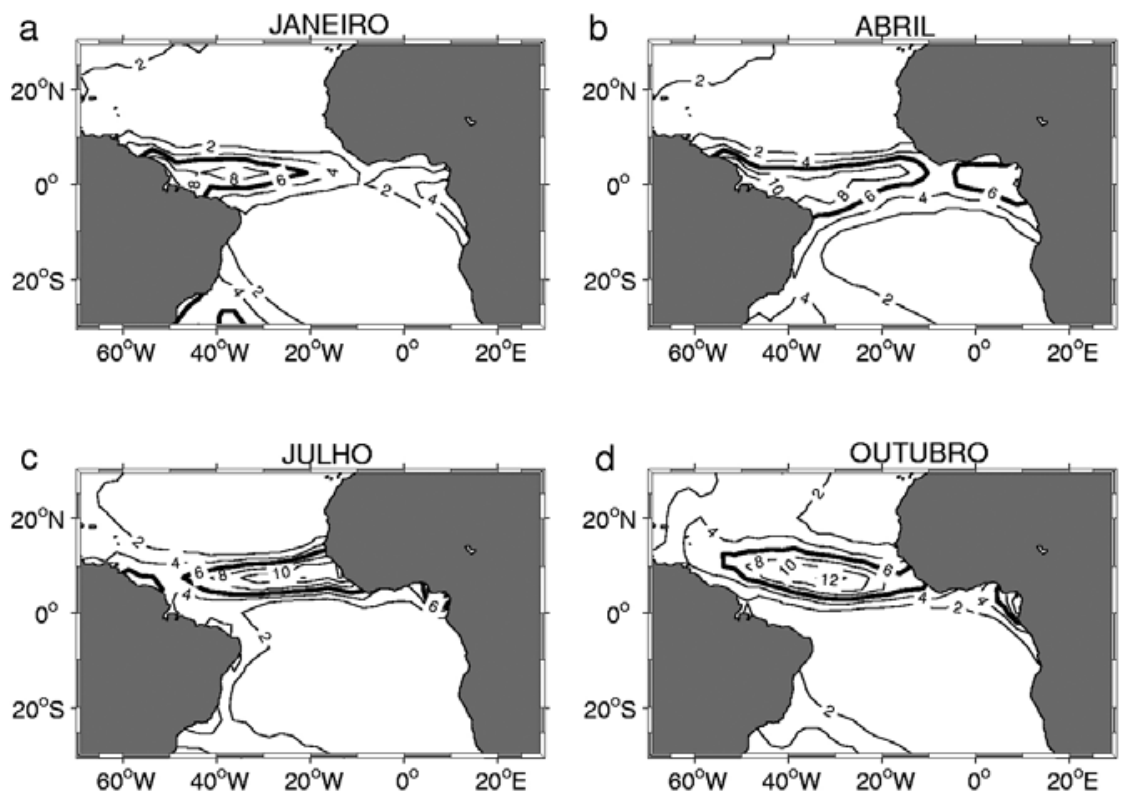

Figura 3 - Precipitacão média para os meses de (a) janeiro, (b) abril, (c) julho e (d) outubro, no Atlântico Tropical. Em destaque a região com precipitação superior a $6 \mathrm{~mm} \mathrm{dia}^{-1}$. 0 intervalo das isolinhas é de $2 \mathrm{~mm} \mathrm{dia}^{-1}$.

subtrópicos de ambos hemisférios. É nessas regiões que ocorre a subsidência de ar proveniente do ramo descendente da célula térmica de Hadley, inibindo a formação de nuvens e, suprimindo conseqüentemente, a precipitação. A diferença entre os meses na posição da faixa de máxima PREC mostra o deslocamento meridional da ZCIT ao longo do ano, localizando-se mais ao sul nos meses de janeiro e abril e mais ao norte em julho e outubro.

A Figura 4 exibe a variação anual dos dados com a latitude 
para o meridiano de $23,75^{\circ} \mathrm{W}$. Essa longitude foi escolhida, por separar o Atlântico Tropical em todas as latitudes sobre o oceano. Pode-se confirmar o deslocamento meridional descrito anteriormente através da Figura 4. A distribuição anual de TSM (Figura 4a) é resultado da dinâmica dos giros subtropicais, que fazem com que as regiões leste dos oceanos sejam de água mais fria, enquanto as regiões oeste possuem valores de TSM mais elevados. É interessante notar que a faixa de $\mathrm{TSM}>27^{\circ} \mathrm{C}$ atinge maiores latitudes no hemisfério sul (chega até $25^{\circ} \mathrm{S}$ em fevereiro e março), do que no hemisfério norte (não atinge $20^{\circ} \mathrm{N}$ ). Apesar disso a faixa da isoterma de $28^{\circ} \mathrm{C}$ permanece mais tempo no Hemisfério Norte do que no Hemisfério Sul.
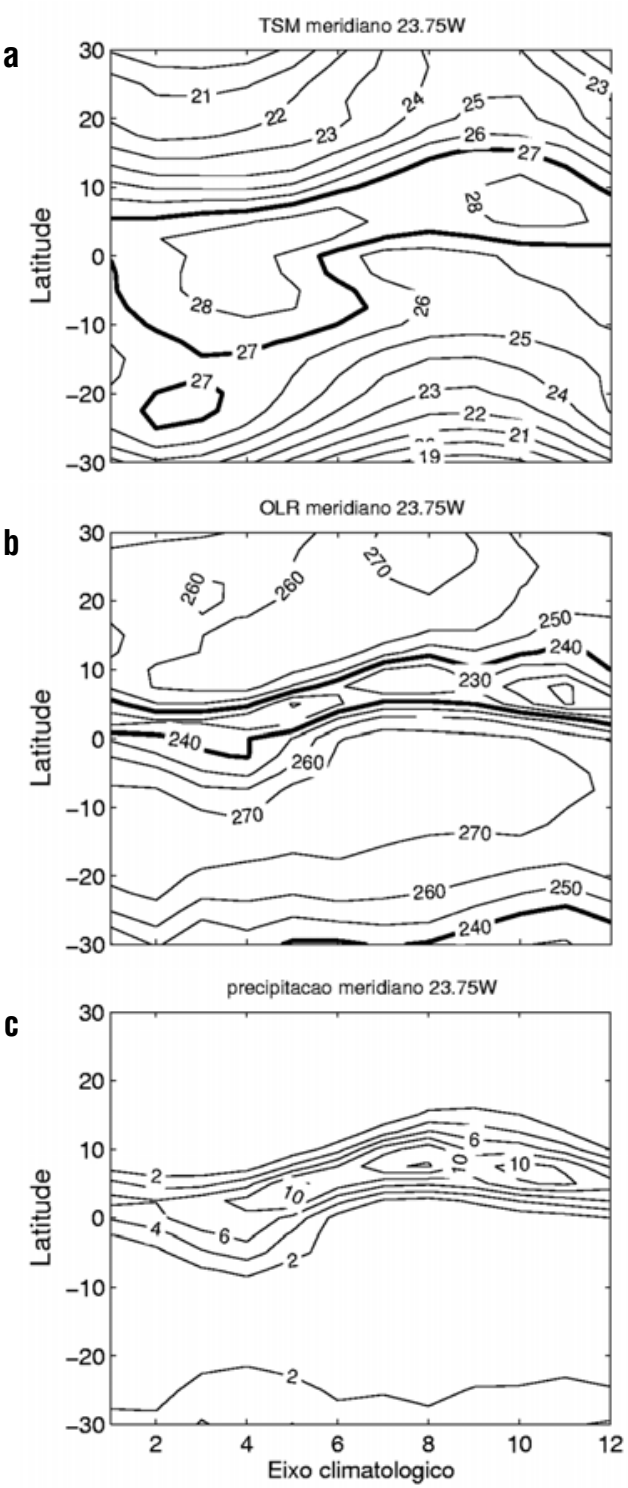

Figura 4 - Diagrama de Latitude vs. Tempo para o meridiano de $23,75^{\circ} \mathrm{W}$, com a série climatológica de 1 (Janeiro) até 12 (Dezembro) para a (a) TSM, (b) ROL e (c) PREC.
A faixa de menor ROL (Figura 4b) se encontra deslocada para o Hemisfério Norte, coincidindo com o Equador meteorológico. Pode-se observar que os valores de $\mathrm{ROL}<240 \mathrm{Wm}^{-2}$ permanecem durante praticamente todo 0 ano no hemisfério norte, chegando a próximo de $14^{\circ} \mathrm{N}$ no mês de novembro, enquanto que sua posição mais ao sul não ultrapassa $05^{\circ} \mathrm{S}$ em março e abril.

A variação anual da PREC (Figura $4 c$ ) é bastante similar a da ROL (Figura 4b), onde a grande área em que não há precipitação coincide com os maiores valores anuais de ROL (no centro do Atlântico Tropical). Em geral, essa região sofre efeito do ar frio do ramo descendente da célula de Hadley, originária da Convergência Intertropical, cuja ausência de umidade impede a formação de nuvens (Graham \& Barnett, 1987).

Pelas Figuras 4a e 4b discutidas acima, nota-se que a distribuição dos valores de temperatura e ROL $\left(27^{\circ} \mathrm{C}\right.$ e 240 Wm$\left.{ }^{-2}\right)$ estão deslocados para o hemisfério norte.

\section{Correlações}

Em escala global a correlação TSM-ROL já é bem conhecida, nos trópicos quanto maior for a TSM menor será a ROL, e nos extratrópicos quanto maior for a TSM, maior será a ROL. Tal fato é explicado pela ausência de formação de nuvens de convecção profunda nos extratrópicos.

A Figura 5 mostra detalhadamente a distribuição da correlação entre ROL e TSM no Oceano Atlântico. Quatro pontos de grade foram selecionados por apresentarem coeficientes de correlação distintos situados dentro da região do Atlântico tropical $\left(20^{\circ} \mathrm{N}-20^{\circ} \mathrm{S}\right)$, conforme Tabela 1.

Tabela 1 - Localização dos quatro pontos selecionados e suas respectivas correlações TSM-ROL.

\begin{tabular}{|c|c|c|c|c|}
\hline \multirow{2}{*}{} & \multicolumn{4}{|c|}{ Pontos } \\
\cline { 2 - 5 } & 1 & 2 & 3 & 4 \\
\hline \multirow{2}{*}{ Localização } & $18,75^{\circ} \mathrm{W}$ & $28,75^{\circ} \mathrm{W}$ & $38,75^{\circ} \mathrm{W}$ & $6,25^{\circ} \mathrm{W}$ \\
\cline { 2 - 5 } & $0^{\circ}$ & $7,5^{\circ} \mathrm{S}$ & $2,5^{\circ} \mathrm{N}$ & $15^{\circ} \mathrm{S}$ \\
\hline Correlação & $-0,81$ & $-0,53$ & $+0,25$ & $+0,90$ \\
\hline
\end{tabular}

0 primeiro ponto se situa em $18,75^{\circ} \mathrm{W}$ e $0^{\circ}$ e apresenta coeficiente de correlação TSM-ROL de $-0,81$, considerado bastante alto. 0 diagrama de dispersão correspondente (Figura 6a) apresenta uma curva que demonstra a correlação negativa entre TSM e ROL. Nota-se a partir $26^{\circ} \mathrm{C}$ uma queda na ROL de $270 \mathrm{Wm}^{-2}$ para $230 \mathrm{Wm}^{-2}$ em aproximadamente $29^{\circ} \mathrm{C}$, com valor mínimo de 220 $\mathrm{Wm}^{-2}$. Segundo Lau et al. (1997), a atividade de convecção profunda se inicia com ROL $<240 \mathrm{Wm}^{-2}$. Isso condiz com o gráfico de dispersão para esse ponto, onde pode se observar que a partir de $240 \mathrm{~W} / \mathrm{m}^{-2}$, a PREC aumenta com a queda da ROL e atinge seus maiores valores, $10 \mathrm{~mm} / \mathrm{dia}$, após $240 \mathrm{Wm}^{-2}$. 


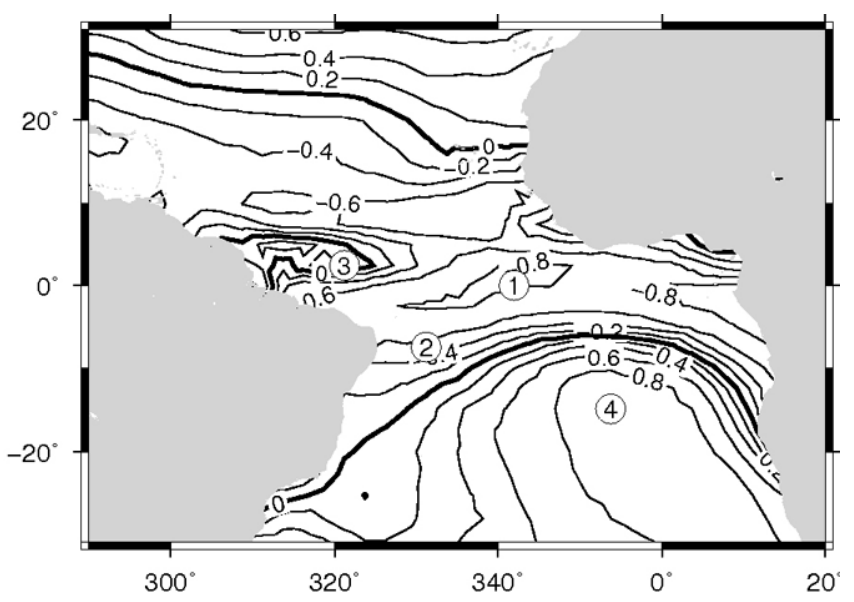

Figura 5 - Superfície de correlação entre TSM e ROL para a região do Atlântico Tropical. Localização dos pontos selecionados: ponto $1\left(18,75^{\circ} \mathrm{W}-0^{\circ}\right)$, ponto $2\left(28,75^{\circ} \mathrm{W}-7,5^{\circ} \mathrm{S}\right)$, ponto $3\left(38,75^{\circ} \mathrm{W}-2,5^{\circ} \mathrm{N}\right)$ e ponto $4\left(6,25^{\circ} \mathrm{W}-15^{\circ} \mathrm{S}\right)$.

a

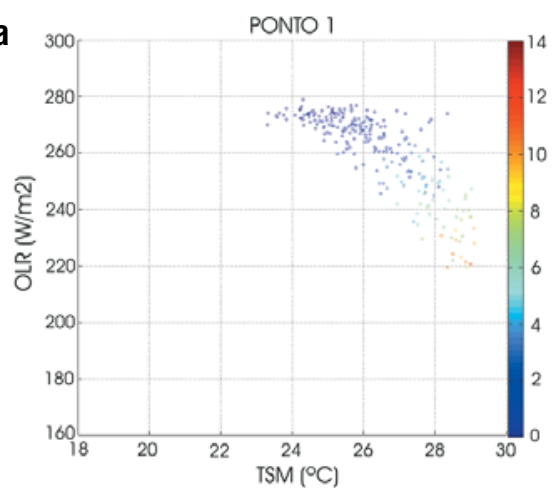

C

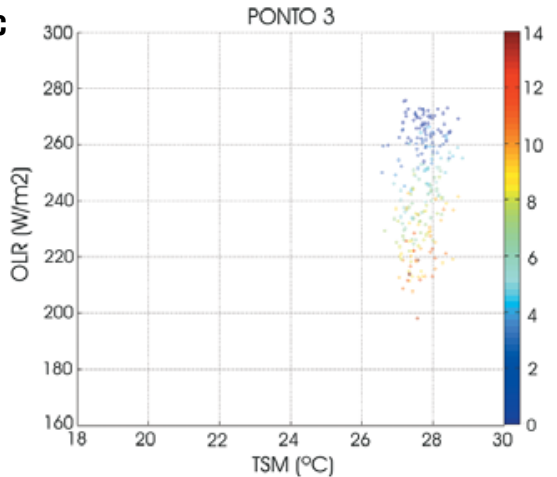

b $\quad$ PONTO 2

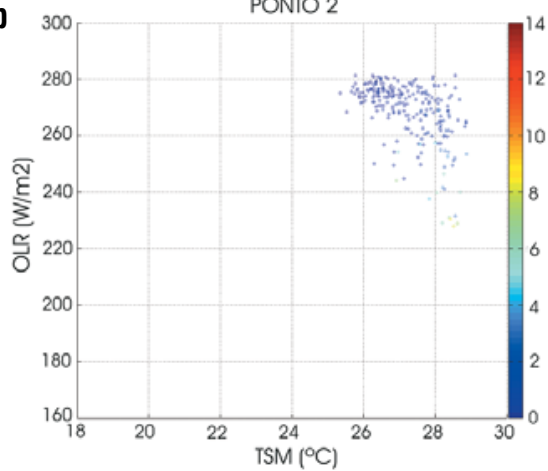

d

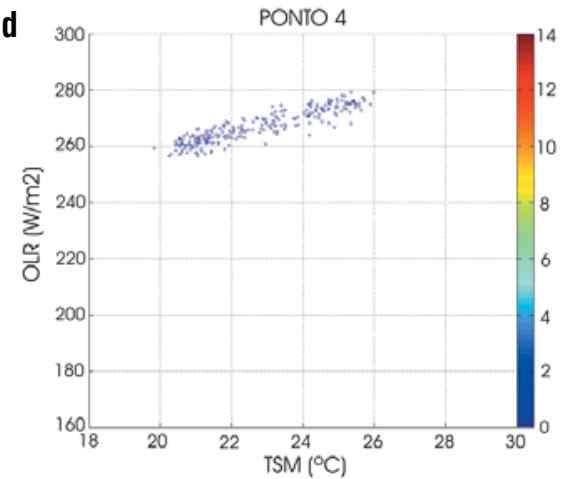

Figura 6 - Diagrama de dispersão envolvendo TSM, ROL e PREC para: (a) ponto $1\left(18.75^{\circ} \mathrm{W}-0^{\circ}\right)$, (b) ponto $2\left(28.75^{\circ} \mathrm{W}\right.$ $\left.7.5^{\circ} \mathrm{S}\right)$, (c) ponto $3\left(38.75^{\circ} \mathrm{W}-2.5^{\circ} \mathrm{N}\right)$ e (d) ponto $4\left(6.25^{\circ} \mathrm{W}-15^{\circ} \mathrm{S}\right)$.

Os dois pontos seguintes, se localizam em $28,75^{\circ} \mathrm{W}-7,5^{\circ} \mathrm{S}$ e $38.75^{\circ} \mathrm{W}-2.5^{\circ} \mathrm{N}$, possuindo índice de correlação de $-0,53$ e $+0,25$, respectivamente. 0 gráfico de dispersão para esses pontos (Figuras 6b e 6c) apresenta uma distribuição consistente com as correlações encontradas. Para 0 segundo ponto (Figura 6b), o que se vê é uma distribuição onde a TSM varia de 25 a $29^{\circ} \mathrm{C}$ e a ROL, com exceção de alguns poucos pontos, não decai para menos de $240 \mathrm{Wm}^{-2}$, indicando a ausência da atividade de convecção profunda.

0 terceiro ponto (Figura 6c) possui uma faixa estreita de 
variação de temperatura, de 27 a $29^{\circ} \mathrm{C}$, para uma grande variação de ROL, de 280 a $210 \mathrm{Wm}^{-2}$. A maior precipitação acontece quando a $\mathrm{ROL}<240 \mathrm{Wm}^{-2}$. Esse ponto é particularmente interessante porque a região é coincidente com a ZCIT e também com a região em que ocorre a retroflexão da Corrente Norte do Brasil (Silveira et al., 2000). Embora apresente uma grande quantidade de precipitação, possui baixos níveis de correlação. Ressalta-se que apesar da elevada TSM (entre $27^{\circ}$ e $29^{\circ} \mathrm{C}$ ), encontra-se valores de ROL que não indicam atividade de convecção profunda $\left(\mathrm{ROL}<240 \mathrm{Wm}^{-2}\right)$. Tal fato, sugere que nesse local, a convecção sofre influência de outros processos, além das variações da TSM local.

0 quarto ponto (Figura $6 \mathrm{~d}$ ), localizado em $6,25^{\circ} \mathrm{W}$ e $15^{\circ} \mathrm{S}$, possui uma correlação positiva bastante alta, $+0,90.0$ diagrama de dispersão mostrado indica uma relação linear positiva entre a TSM e a ROL. Com a TSM variando de $20^{\circ}$ a $26^{\circ} \mathrm{C}$ não há formação de convecção profunda, concordante com 0 que Zhang (1993) achou para o Pacífico.

A comparação entre a correlação espacial das séries temporais das três variáveis (TSM-ROL (Figura 5), ROL-PREC (Figura 8a) e TSM-PREC (Figura 9a) com a correlação espacial das suas séries de anomalias (Figuras 7, 8b e 9b) permitiram verificar que grande parte da correlação entre a TSM e as outras duas variáveis se deve ao seu ciclo sazonal climatológico, já que a correlação entre as séries temporais (Figuras 5 e 9a) possui valores mais elevados do que aquela entre as séries de anomalias (Figuras $7 \mathrm{e}$ 9b). Exceção ocorre para a ROL e a PREC, onde a correlação das anomalias (Figura 8b) possui valores tão elevados quanto entre as séries temporais (Figura 8a). Através das áreas com maiores coeficientes de correlação e dos diagramas Latitude vs. Tempo foi estabelecida uma região, onde a PREC e a ROL parecem estar mais bem correlacionadas com a TSM e essa região se encontra deslocada para o hemisfério norte.

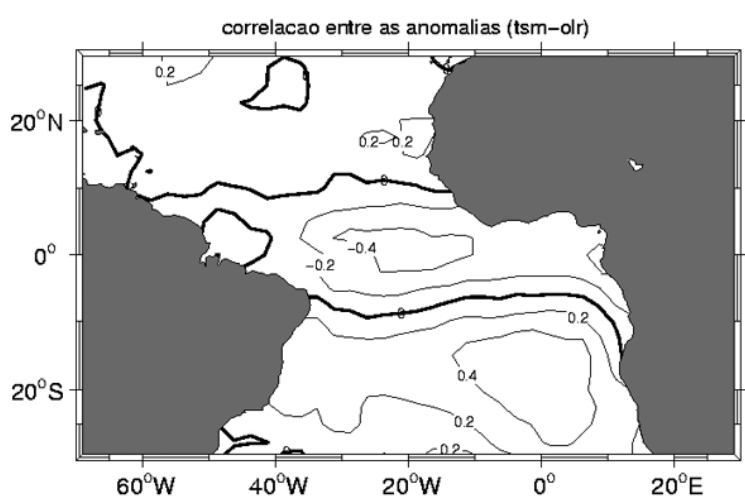

Figura 7 - Gráficos da superfície de correlação entre a TSM e a ROL para as séries das anomalias. Intervalo das isolinhas de 0,2. a

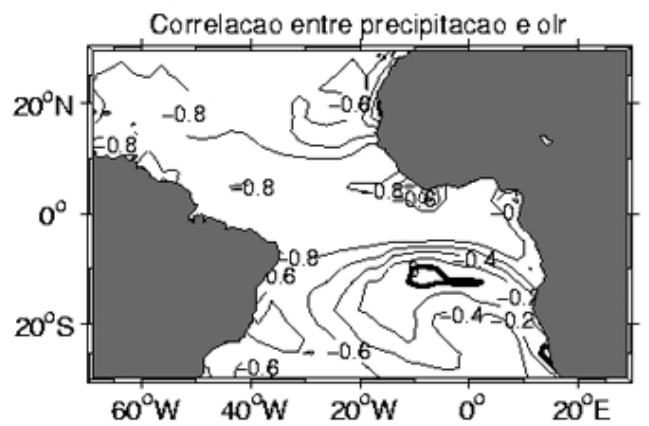

b

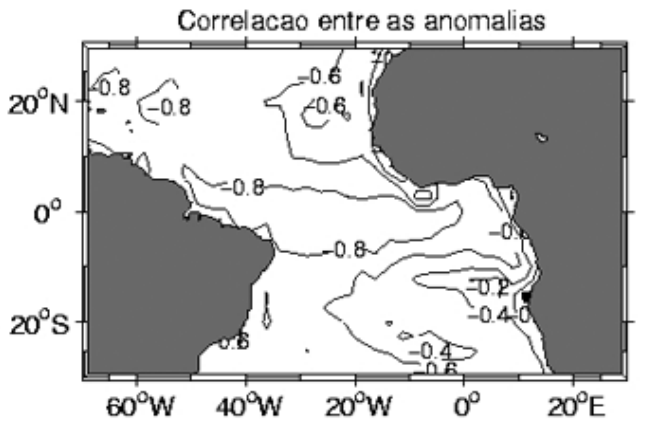

Figura 8 - Gráficos da superfície de correlação entre a PREC e a ROL (a) para as séries temporais e (b) para as séries das anomalias. Intervalo das isolinhas de 0,2 .

a

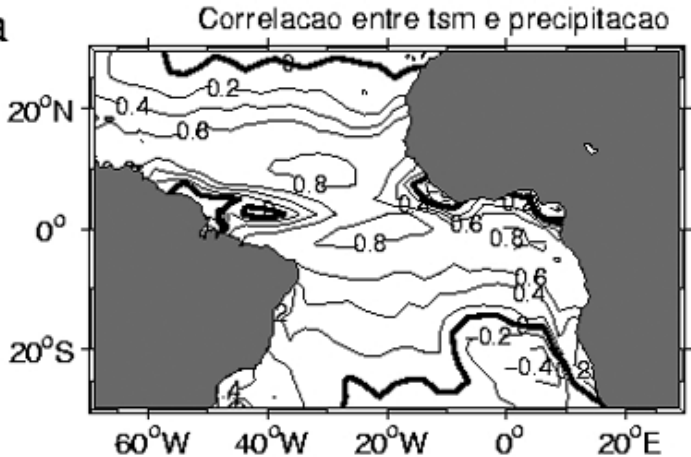

b

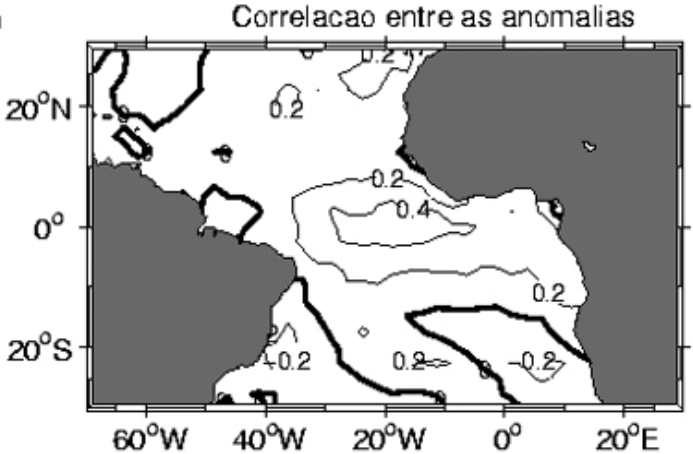

Figura 9 - Gráficos da superfície de correlação entre a PREC e a TSM (a) para as séries temporais e (b) para as séries das anomalias. Intervalo das isolinhas de 0,2 . 

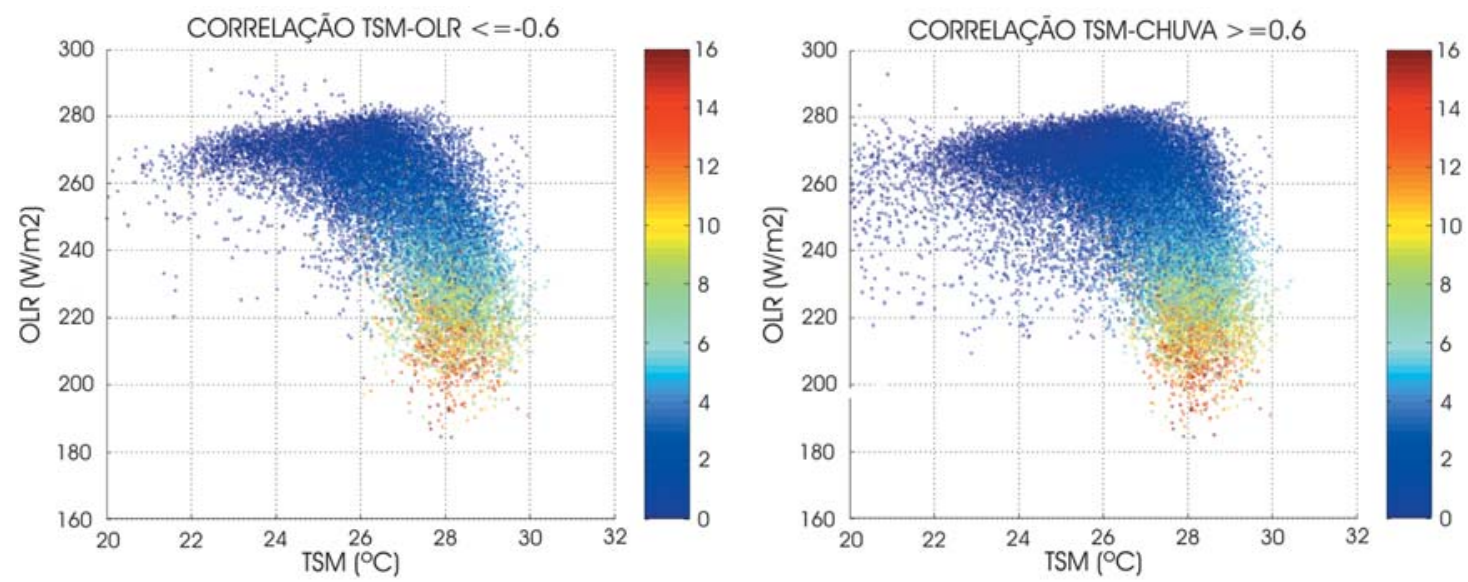

Figura 10 - Diagramas de dispersão para os pontos com coeficientes de correlação entre (a) ROL-TSM $\leq-0,6$ e (b) TSM-PREC $\geq 0,6$. A barra de cor indica a quantidade de precipitação $\left(\mathrm{mm} \mathrm{dia}^{-1}\right)$.
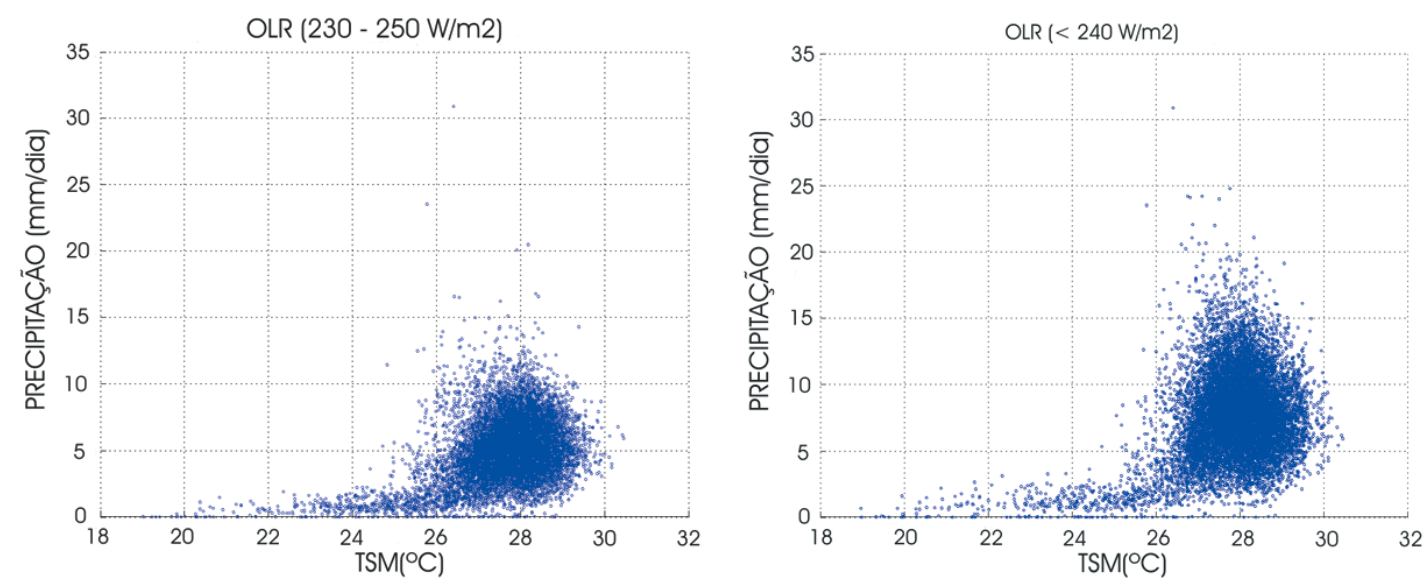

Figura 11 - Diagramas de dispersão para os pontos com valor de ROL (a) entre $230-250 \mathrm{Wm}^{-2}$ e (b) ROL $<240 \mathrm{Wm}^{-2}$, na região estudada.

\section{Análise da dispersão}

Observando os diagramas de dispersão dos pontos onde os coeficientes de correlação TSM-PREC $\geq 0$, 6 (Figura 10a) e TSM-ROL $\leq-0.6$ (Figura 10b), nota-se uma quebra da tendência dos pontos a partir da faixa de TSM entre 27 e $28^{\circ} \mathrm{C}$, possivelmente a faixa de temperatura que aciona o mecanismo de convecção profunda no Atlântico Tropical.

0 gráfico da Figura 11a engloba apenas os pontos na faixa de ROL 230-250 $\mathrm{Wm}^{-2}$, considerando que a convecção profunda se inicia em $240 \mathrm{Wm}^{-2}$. Existe um pico de PREC quando a TSM chega a $28^{\circ} \mathrm{C}$ e posterior decréscimo da mesma entre 28 a $30^{\circ} \mathrm{C}$. Isso significa que para essa faixa de ROL, a máxima PREC ocorre para a TSM em torno de $28^{\circ} \mathrm{C}$. A Figura 11a mostra ainda que a PREC aumenta consideravelmente (acima de $5 \mathrm{~mm} / \mathrm{dia}$ ), após a TSM atingir $26^{\circ} \mathrm{C}$.
A Figura 11b, que engloba os valores de TSM e PREC dentro do regime de convecção profunda ( $\mathrm{ROL}<240 \mathrm{Wm}^{-2}$ ), apresenta valores similares. É possível verificar a convergência dos valores mais altos de PREC quando a TSM se aproxima de $28^{\circ} \mathrm{C}$, semelhante à Figura 11a, porém a precipitação varia mais bruscamente com a TSM dentro de um regime convectivo, atingindo maiores valores (20 mm/dia) após $26^{\circ} \mathrm{C}$ e decaindo rapidamente após $28^{\circ} \mathrm{C}$.

A Figura 12a mostra na ordenada o número de observações para os valores de TSM variando entre $16^{\circ} \mathrm{C}$ e $32^{\circ} \mathrm{C}$, mostrados na abscissa. Pode-se verificar que a maioria dos valores observados corresponde à faixa de TSM entre 26 e $29^{\circ} \mathrm{C}$, e praticamente não há observações para TSM $>30^{\circ} \mathrm{C}$ e TSM $<20^{\circ} \mathrm{C}$. Os valores observados para ROL $<240 \mathrm{Wm}^{-2}$, vistos na curva interna da Figura 12a, também estão concentrados na faixa de TSM entre 26 
e $29^{\circ} \mathrm{C}$, com um pico entre 27 e $28^{\circ} \mathrm{C}$. A Figura $14 \mathrm{~b}$ corresponde à probabilidade de ser encontrada $\mathrm{ROL}<240 \mathrm{Wm}^{-2}$ para cada valor de TSM, conforme Eq.(1) descrita na metodologia. Os valores inferiores a $22^{\circ} \mathrm{C}$ não devem ser levados em consideração pois não caracterizam áreas de convecção profunda. A baixa ROL encontrada para esses valores é resultante da própria TSM e não do efeito da cobertura de nuvens. Pode-se notar um claro aumento na probabilidade após $26^{\circ} \mathrm{C}$, saltando de menos de $10 \%$ para valores superiores a $90 \%$ quando atinge a marca próxima de $30^{\circ} \mathrm{C}$. Também cabe ressaltar a passagem da probabilidade para além de $50 \%$ quando a TSM atinge $28^{\circ} \mathrm{C}$.

A Figura 13a representa o número total de observações em função da ROL para cada faixa de TSM. A maior parte dos valores está situada na faixa de ROL $>240 \mathrm{Wm}^{-2}$, indicando que apenas uma pequena área da região de estudo apresenta ROL atingindo 0 valor limite para dar início à convecção profunda. Portanto é interessante localizar os valores onde a ROL é inferior a $240 \mathrm{~W} / \mathrm{m}^{2}$ e identificar suas características em comum. A Figura 13b mostra a probabilidade de ocorrência dos valores de ROL para faixas específicas de TSM. Podemos verificar que para a faixa de TSM entre 26 e $27^{\circ} \mathrm{C}$, a maior probabilidade de ocorrência se concentra em valores acima de $240 \mathrm{Wm}^{-2}$, com a probabilidade diminuindo para valores de ROL menores. Acontece o contrário para as faixas de TSM entre 27 e $29^{\circ} \mathrm{C}$. A faixa de $27-28^{\circ} \mathrm{C}$ possui a maior probabilidade de ocorrência para valores de ROL próximos de $240 \mathrm{Wm}^{-2}$, enquanto a faixa de $28-29^{\circ} \mathrm{C}$ possui a maior probabilidade para valores próximos de $220 \mathrm{Wm}^{-2}$.

Para tentar localizar a faixa de temperatura que corresponderia ao gatilho do mecanismo de convecção profunda, os dados de TSM foram agrupados em faixas de temperatura e os valores de ROL e PREC foram analisados em função de sua variância e suas médias. Supõe-se que a maior variância da ROL indique a faixa de TSM onde a convecção profunda teria início, considerando que o maior espalhamento dos valores de ROL correspondem a transição entre a ausência de nuvens (altos valores de ROL) e a presença delas em altas altitudes (baixos valores de ROL). Também vale salientar que muitas regiões encontram-se em áreas de TSM no limiar do valor crítico e que dependendo de sua variação são suscetíveis ao desencadeamento do mecanismo de convecção profunda. Portanto, é de grande interesse a identificação da variância de ROL e PREC de acordo com a TSM para caracterizar a ocorrência da convecção profunda.

Na Tabela 2, para a faixa de TSM entre 26 e $27^{\circ} \mathrm{C}$, obteve-se a menor variância e a menor média de PREC, pois em geral nessas condições a convecção profunda não se desenvolve.

$\mathrm{Na}$ faixa de TSM entre 28 e $29^{\circ} \mathrm{C}$, fica claro que essa região já está sob efeito da convecção profunda, pois a média da ROL se situa abaixo de $240 \mathrm{Wm}^{-2}$, ou seja, apresenta média inferior à da faixa na qual o mecanismo de convecção profunda se inicia. Essa faixa de temperatura possui a maior média de precipitação (confirmando o dado acima), porém a sua variância para os valores de ROL é inferior a variância da faixa de TSM entre 27 e $28^{\circ} \mathrm{C}$.

A máxima variância encontrada se situa dentro da faixa de TSM entre 27 e $28^{\circ} \mathrm{C}$, a média de ROL para essa faixa de TSM é de $245 \mathrm{Wm}^{-2}$, ligeiramente acima da ROL de $240 \mathrm{Wm}^{-2}$ indicadora de convecção profunda, porém bastante próximo a ela. A variância da PREC também é bastante alta, praticamente igual à variância encontrada para a faixa de TSM entre 27,5 e $28,5^{\circ} \mathrm{C}$.

A faixa de TSM entre 27,5 e $28,5^{\circ} \mathrm{C}$ possui valores similares à faixa de TSM entre 27 a $28^{\circ} \mathrm{C}$. Sua média de precipitação é ligeiramente maior, e a média da ROL praticamente coincide com a faixa de $240 \mathrm{Wm}^{-2}$, correspondente ao gatilho do mecanismo de convecção profunda.

\section{CONCLUSÕES}

Com esse trabalho foi possivel identificar os valores de ROL, TSM críticos correspondentes ao mecanismo da convecção profunda no Atlântico Tropical. Através das análises realizadas observouse que no Atlântico Tropical a convecção profunda está presente em áreas de TSM superiores a $27^{\circ} \mathrm{C}$. A TSM raramente ultrapassa $30^{\circ} \mathrm{C}$. Contudo, na região do Atlântico Tropical, existem locais onde a correlação entre TSM e ROL apresenta tanto valores elevados (negativos e positivos) quanto baixos, sugerindo que a resposta termodinâmica da ROL é influenciada além da TSM local também por processos gerados em campos remotos.

Uma hipótese, seria o fato da região em que se situa o ponto 3 (Figura 5), ter seu regime convectivo associado a ZCIT, que por sua vez sofre influencia de diversos processos gerados tanto na região tropical como em locais extra-trópico.

Por exemplo, Haarsma et al. (2003) em um estudo numérico, simula o efeito do Dipolo do Atlântico Sul e concluí que a ZCIT em períodos de ocorrência do dipolo, se desloca anomalamente para 0 sul. 0 deslocamento do ponto da convergência dos ventos, faz com que a convecção siga esse deslocamento e ocorra em outro local. Isso poderia corresponder a uma possível explicação para a região em que se situa o ponto 3 (Figura 5), que apesar da elevada TSM apresenta uma fraca correlação com a ROL, nesse caso, modos de variabilidade como o Dipolo do Atlântico Sul, apesar de não afetar a TSM local, estariam afetando remotamente a convecção no local.

Fica claro também a mudança no regime de precipitação para 

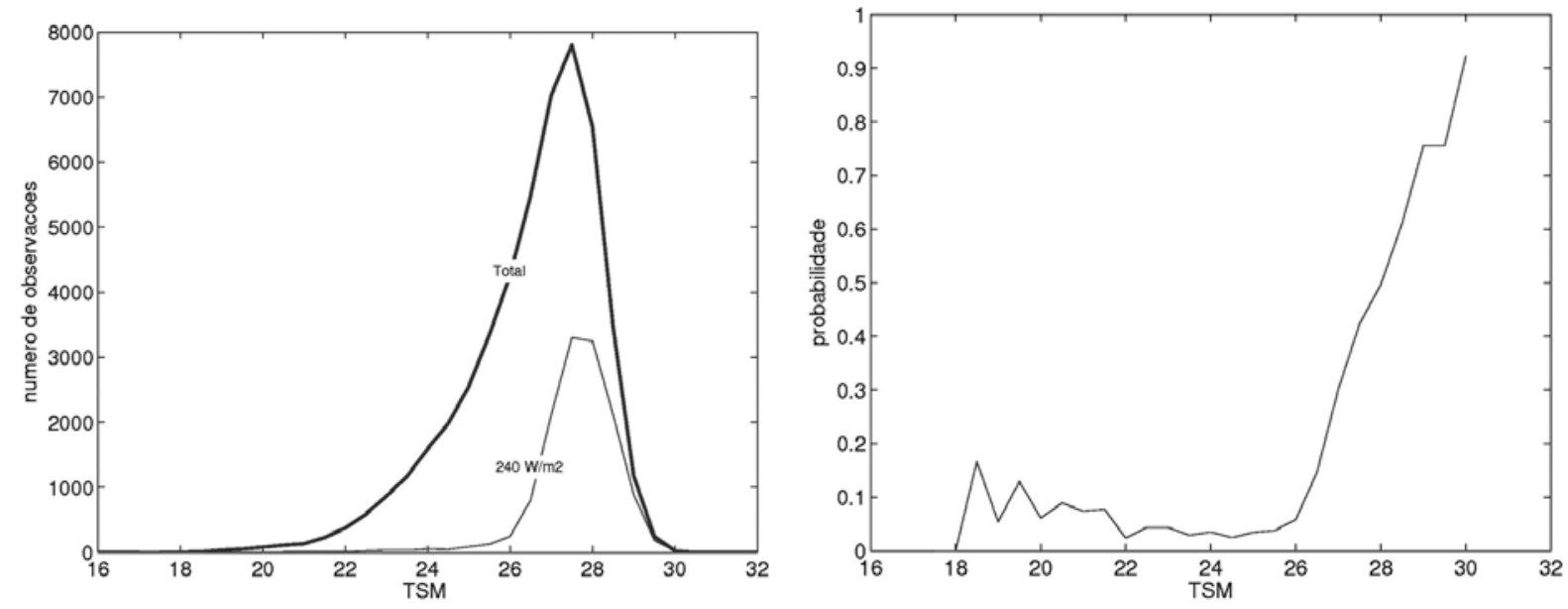

Figura 12 - Diagramas de dispersão para os pontos com valor de ROL (a) entre 230-250 $\mathrm{Wm}^{-2}$ e (b) ROL $<240 \mathrm{Wm}^{-2}$, na região estudada.
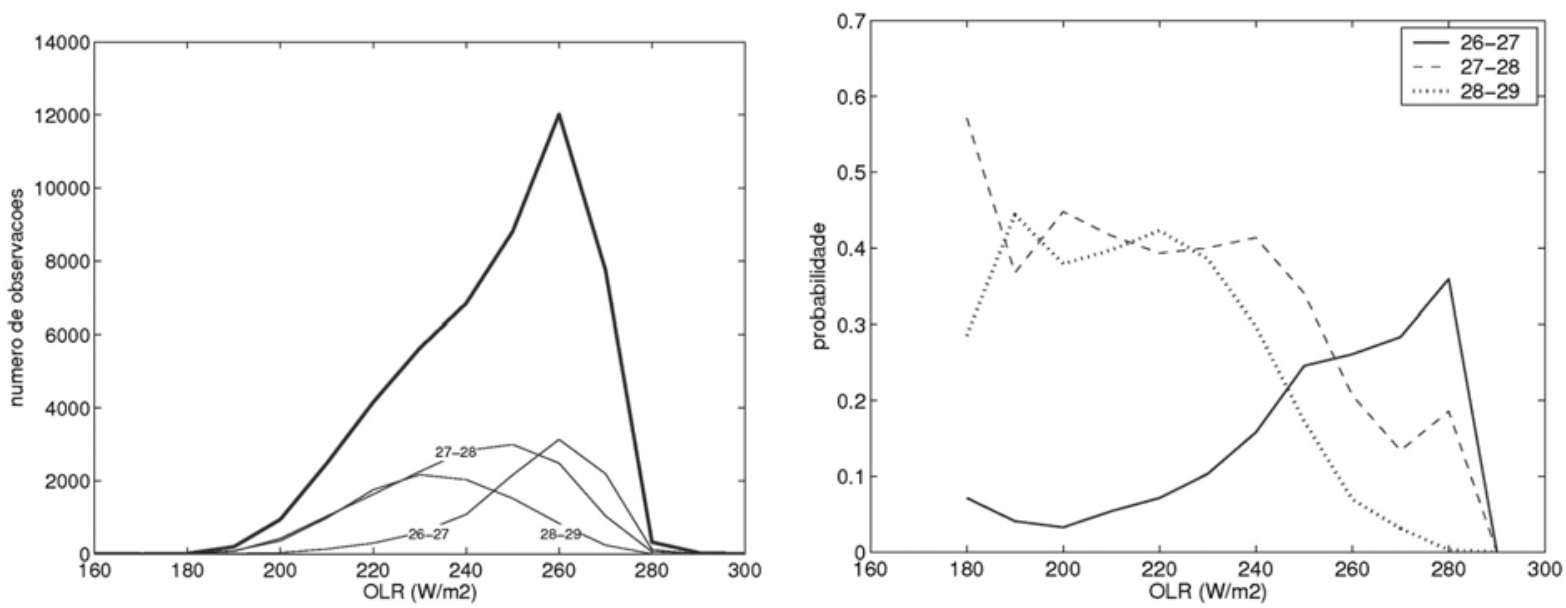

Figura 13 - Probabilidade da ocorrência de valores de ROL para diferentes faixas de TSM. (a) Número total de valores de ROL observados (linha grossa) e número de valores de ROL para diferentes faixas de TSM $\left(26-27^{\circ} \mathrm{C}, 27-28^{\circ} \mathrm{C}\right.$ e $\left.28-29^{\circ} \mathrm{C}\right)$. (b) Probabilidade de encontrar valores de ROL para cada faixa de TSM.

Tabela 2 - Variância e média dos valores de ROL e PREC, para determinadas faixas de TSM.

\begin{tabular}{|c|c|c|c|c|c|c|}
\hline & ${\text { TSM }\left({ }^{\circ} \mathrm{C}\right)}[26$ 27] & {$[26,5$ 27,5] } & {$[27$ 28 $]$} & {$[27,5$ 28,5] } & {$[28$ 29] } \\
\hline \multirow{2}{*}{ ROL } & Variância & 203 & 297 & 330 & 310 & 279 \\
& Média & 259 & 252 & 245 & 241 & 238 \\
\hline \multirow{2}{*}{ PREC } & Variância & 5,4 & 9,3 & 11,1 & 11,2 & 10,6 \\
& Média & 2,1 & 3,5 & 4,8 & 5,6 & 5,9 \\
\hline
\end{tabular}

TSM superior a $26^{\circ} \mathrm{C}$, concordante com Zhang (1993), aumentando consideravelmente a quantidade de precipitação ao atingir a marca de $28^{\circ} \mathrm{C}$, e decaindo novamente quando a TSM se aproxima de $30^{\circ} \mathrm{C}$. Waliser et al. (1993), afirmam que a máxima convecção não ocorre nas TSM mais elevadas, analogamente 0 mesmo é válido para a precipitação na região de estudo, onde 0 máximo da precipitação ocorre próximo da TSM de $28^{\circ} \mathrm{C}$.

Ressalta-se ainda que para se ter PREC proveniente da convecção profunda, deve-se considerar que a faixa de TSM entre 27 e $28^{\circ} \mathrm{C}$, dentro dos locais de elevada correlação entre ROL-TSM, 
contém a TSM crítica que seria responsável pelo início da atividade convectiva. Portanto, 0 aumento da PREC em TSM inferior a $27^{\circ} \mathrm{C}$ deve-se, provavelmente, a outros tipos de nuvens diferentes daquelas oriundas da convecção profunda.

\section{AGRADECIMENTOS}

Este trabalho foi financiado pelo PIBIC/CNPq.

\section{REFERÊNCIAS}

CHELLIAH M \& ARKIN P. 1992. Large-scale interannual variability of monthly outgoing longwave radiation anomalies over the global tropics. J. Climate, 5: 371-389.

DUTTON JF, CRIS J POULSEN \& JENNI L EVANS. 2000. The effect of global climate change on the regions of tropical convection in CSM1. Geophys. Res. Lett., 27(19): 3049-3052.

GRAHAM NE \& BARNETT TP. 1987. Sea surface temperature, surface wind divergence and convection over tropical oceans. Science, 238 : 657-659.

HAARSMA RJ, CAMPOS EJD \& MOLTENI F. 2003. Atmospheric response to South Atlantic SST dipole. Geophys. Res. Lett., 30(16): 1864.

LAU K-M, WU H-T \& BONY S. 1997. The role of large-scale atmospheric circulation in the relationship between tropical convection and sea surface temperature. J. Climate, 10: 318-392.

LINDZEN RS. 1990. Some Coolness Concerning Global Warning. Bulletin of the American Meteorological Society, 71: 288-299.

LIEBMANN B \& SMITH CA. 1996. Description of a complete (interpolate) outgoing longwave dataset. Bulletin of the American Meteorological Society, 77 : 1275-1277.

MOURA AD \& SHUKLA J. 1981. On the Dynamics of Droughts in Northeast Brazil: Observations, Theory and Numerical Experiments with a General Circulation Model. Journal of the Atmospheric Sciences, 38 : 2653-2675
NOBRE P. 1996. Variabilidade interanual do Atlântico tropical e sua influência no clima da América do Sul. Climanálise - Edição Comemorativa.

PEZZI LP \& CAVALCANTI FA. 2001. The relative importance of ENSO and tropical Atlantic sea surface temperature anomalies for seasonal precipitation over South America: a numerical study. Climate Dynamics, 17: 205-212.

REYNOLDS RW, RAYNER NA, SMITH TM, STOKES DC \& WANG W. 2002. An Improved In Situ and Satellite SST Analysis for Climate. J. Climate, 15: $1609-1625$.

SERVAIN J. 1991. Simple climatic indices for the tropical Atlantic Ocean and some applications. J. Geophys. Research, 96: 15137-15146.

SILVEIRA ICA, BROWN WS \& FLIERL GR. 2000. Dynamics of the North Brazil Current Retroflection from the WESTRAX observations. J. Geophys. Research, 105: 28559-28583.

TOMCZAK M \& GODFREY JS. 2003. Regional Oceanography: an Introduction 2ed. Daya Publishing House, Delhi. Disponível em: <http:// gaea.es.flinders.edu.au/ mattom/regoc/pdfversion.html>.

WALISER DE, GRAHAM NE \& GAUTIER C. 1993. Comparison of the Highly Reflective Cloud and Outgoing Longwave Radiation Datasets for Use in Estimating Tropical Deep Convection, J. Climate, 6: 331-353.

XIE P \& ARKIN A. 1998. Global monthly precipitation estimates from satellite-observed outgoing longwave radiation. J. Climate, 11: 137164.

XIE P \& ARKIN A. 1997. Global Precipitation: A 17-Year Monthly Analysis Based on Gauge Observations, Satellite Estimates, and Numerical Model Outputs. Bulletin of the American Meteorological Society, 78: 2539-2558.

ZHANG C. 1993. Large-scale variability of atmospheric deep convection in relation to sea surface temperature in the tropics. J. Climate, 6 : 1898-1913.

\section{NOTAS SOBRE OS AUTORES}

Tiago Nicolosi Bomventi. Aluno de graduação em Oceanografia no Instituto Oceanográfico da Universidade de São Paulo. Atualmente fazendo iniciação científica na área de Oceanografia Física com enfoque em interação oceano-atmosfera.

Ilana Elazari KIein Coaracy Wainer. Professora Livre Docente do departamento de Oceanografia Física do Instituto Oceanográfico da Universidade de São Paulo. Especialista em interação oceano-atmosfera e clima utilizando modelos acoplados de alta complexidade. Além de extensa atividade de pesquisa e ensino, participa dos comitês de direção de programas internacionais como o WCRP (World Climate Research Program), GCOS (Global Climate Observing System) além de participar como especialista em Oceanografia Física de grupo de trabalho do SCAR (Scientific Committee for Antarctic Research).

Andrea Sardinha Taschetto. Bacharel em Física com habilitação em Pesquisa Básica pelo Instituto de Física da Universidade de São Paulo (1999), Mestre (2001) e Doutora (2006) em Oceanografia Física pelo Instituto Oceanográfico da Universidade de São Paulo. Atualmente atua como PostDoc na University of New South Wales, em Sydney, Austrália, na área de Oceanografia Física e Meteorologia. Seus principais interesses são o estudo da variabilidade climática e interação oceano-atmosfera no Hemistério Sul através de modelagem numérica e análises estatísticas em dados observacionais. 